\title{
CARACTERIZAÇÃO DE PLACAS DE CURCUITO IMPRESSO DE CELULARES DESCARTADOS VISANDO À AVALIAÇÃO DE CICLO DE VIDA
}

\author{
TERENA L. M. ${ }^{1}$, ALMEIDA A. F. ${ }^{1}$, VIEIRA M. G. A. ${ }^{1}$
}

${ }^{1}$ Faculdade de Engenharia Química, Universidade Estadual de Campinas. Av. Albert Einstein, 500 - Cidade Universitária "Zeferino Vaz" - C. P. 6066 - CEP: 13083-970CEP 13083-852 Campinas -SP

e-mail: melissagav@feq.unicamp.br

\begin{abstract}
RESUMO - Este trabalho tem como objetivo a obtenção de uma ampla caracterização de placas de circuito impresso de celulares descartados, que inclui classificação granulométrica, ensaios de lixiviação, Microscopia Eletrônica de Varredura e Espectrômetro de Raios X por dispersão de energia (MEV/EDS), Espectrometria de emissão por plasma indutivo (ICP-OES), Espetroscopia no infravermelho (FT-IR) e Cromatografia Iônica. A caracterização deste material é importante para estudo de técnicas de reciclagem e recuperação de metais presentes nas placas.
\end{abstract}

\section{INTRODUÇÃO}

Entre os equipamentos eletroeletrônicos da atualidade, o celular vem merecendo destaque pela grande quantidade que surge no mercado anualmente e em função da geração de resíduos que necessitam de descarte apropriado. Apesar da grande quantidade de resíduo eletroeletrônico gerada, pouco tem sido feito para uma coleta eficiente e reciclagem rentável. Uma das principais dificuldades é na desmontagem, que é uma operação dispendiosa (Yang, 2009). A superação dessas dificuldades é de grande importância para minimizar os danos ao meio ambiente que os componentes destes produto podem causar (Kunnari, 2009).

Entre os componentes do celular, a placa de circuito impresso de celular (CIC) é onde se concentra a grande maioria dos metais preciosos e pesados. Deve-se atentar aos mentais pesados devido ao alto potencial de contaminação quando descartados de maneira incorreta e grandes prejuízos subsequentes. Os metais preciosos se destacam pelo seu alto valor agregado, e sua recuperação e reinserção na cadeia produtiva podem poupar extrações minerais posteriores mais caras e invasivas ambientalmente (Ayeres, 1997).

A caracterização das placas fornece a composição das placas de circuito impresso e é de grande importância para definir processos de reciclagem mais viáveis e vantajosos. A reciclagem desse material é de utilidade pública, pois seu potencial de contaminação do ambiente e danos posteriores é muito grande devido a sua composição tóxica. 


\section{Congresso Brasileiro de Engenharia \\ Química em Iniciação Científica \\ Unicamp - Campinas - SP \\ 19 a 22 de julho de 2015}

\section{MATERIL E MÉTODOS}

Para a realização da caracterização foi moído um quilograma de placas de circuito impresso de celular (CIC) de vários modelos de celulares descartados em moinho de facas.

\subsection{Classificação Granulométrica}

Foi utilizado um agitador de peneiras da marca Produtest para os ensaios de gravimetria. $\mathrm{Na}$ classificação granulométrica foram utilizadas seis peneiras vibratórias e fundo com malhas de $1 \mathrm{~mm} ; 0,71 \mathrm{~mm} ; 0,60 \mathrm{~mm} ; 0,425 \mathrm{~mm} ; 0,18 \mathrm{~mm} ; 0,075 \mathrm{~mm}$. Foi calculado o Diâmetro de Sauter e este foi escolhido para representar o valor médio de diâmetro das partículas moídas.

\subsection{MEV/EDS}

A técnica de Microscopia Eletrônica de Varredura (MEV) foi utilizada com o objetivo de se obter imagens de alta ampliação e detalhamento da superfície do material caracterizado, com o equipamento LEO ElectronMicroscopy/Oxford modelo 440i. Não foi necessária a realização do recobrimento metálico superficial, pois a amostra já possuía material metálico suficiente para que a análise fosse efetuada. O EDS, uma ferramenta do MEV, no modelo 6070, identificou a composição da amostra, de forma semi-quantitativa, em pontos específicos das imagens produzidas pelo MEV.

\subsection{Infravermelho}

Foi realizada análise no Espectrômetro de Infravermelho com Transformada de Fourier (FT-IR), da marca ThermoScientific, modelo Nicolet 6700, utilizando pastilha de $\mathrm{KBr}$. A medida foi feita no modo transmitância na faixa $4000-400 \mathrm{~cm}^{-1}$. Assim, foi possível identificar os grupos funcionais orgânicos presentes na amostra provenientes do material polimérico.

\subsection{ICP-OES e ensaios de lixiviação}

Para análise por ICP-OES com o equipamento Perkin Elmer - 3000 DV foi realizada uma digestão da amostra moída em água régia $\left(\mathrm{HNO}_{3}: \mathrm{HCl}, 1: 3\right)$ na proporção $1 \mathrm{~g}$ de resíduo para $20 \mathrm{~mL}$ de solução durante $24 \mathrm{~h}$ a temperatura ambiente. O liquor lixiviado foi obtido por filtração simples utilizando-se papel de filtro quantitativo de porosidade 7,5 $\mu \mathrm{m}$ e analisado para determinação dos metais presentes. Isso nos permitiu identificar, através de um sistema de detecção de radiação, um elevado número de elementos na amostra. $\mathrm{O}$ material não lixiviado corresponde à fração polimérica e cerâmica, e o lixiviado, aos metais solúveis em água régia. Também foi feita lixiviação ácida em ácido sulfúrico com relação sólido:líquido de $1: 10$ a $75^{\circ} \mathrm{C}$ e pH $=0,5$. Foi coletada uma alíquota após $4 \mathrm{~h}$ e o liquor lixiviado foi analisado por ICP-OES e Cromatografia Iônica. $\mathrm{O}$ material não lixiviado filtrado foi lavado com água deionizada e seco em estufa a $60{ }^{\circ} \mathrm{C}+/-5^{\circ} \mathrm{C}$ por $24 \mathrm{~h}$ e passou por lixiviação ácida em meio oxidante, com ácido sulfúrico e peróxido de hidrogênio nas mesmas condições de temperatura e relação sólido: líquido da lixiviação ácida. Adicionou-se $10 \mathrm{~mL}$ de peróxido de hidrogênio a cada 30 minutos, totalizando $80 \mathrm{~mL}$ após $4 \mathrm{~h}$. O liquor lixiviado foi analisado 
por ICP-OES para identificação dos cátions e Cromatografia Iônica para os ânions (Moraes, 2010).

\section{RESULTADOS E DISCUSSÃO}

\subsection{Análise granulométrica}

O material moído foi separado através de peneiras vibratórias de acordo com seu diâmetro médio. O diâmetro de Sauter obtido que representa o valor médio das partículas moídas foi de $0,2158 \mathrm{~mm}$.

\subsection{Análise morfologia de superfície}

A Figura 1 mostra as imagens da amostra de placas de circuito impresso de celular (CIC) moídas obtidas pela técnica de MEV. A figura 1a refere-se ao material com granulometria média $0,1275 \mathrm{~mm}$; cuja imagem está com uma ampliação de 50 vezes. É possível perceber a heterogeneidade e variedade de espécies na amostra, como já era esperado. Na figura $1 \mathrm{~b}$ e $1 \mathrm{~d}$, com granulometria menor que $0,0375 \mathrm{~mm}$ e ampliação de 500 e 1000 vezes, respectivamente, também é visível a variedade do material e fica mais nítida a diferença de tamanhos entre estes. A figura 1c posssui a mesma granulometria da Figura la e focaliza partes específicas da amostra que ilustra mais detalhes, com uma ampliação de 150 vezes.

Figura 1 - Micrografia eletrônica de varredura da amostra de placas de circuito impresso de celular moídas.
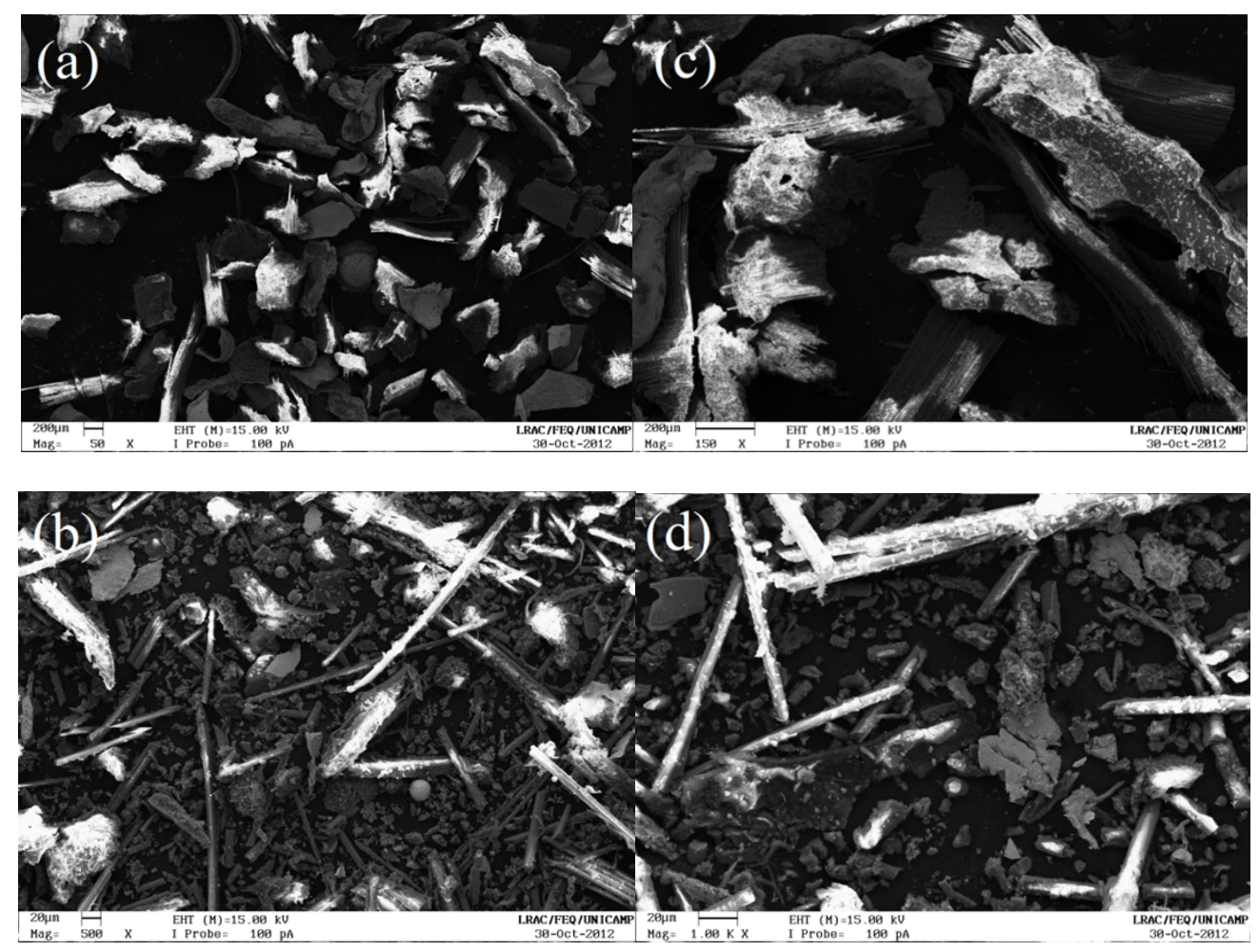


\section{Congresso Brasileiro de Engenharia \\ Química em Iniciação Científica \\ Unicamp - Campinas - SP \\ 19 a 22 de julho de 2015}

\subsection{Composição química por EDS}

Foram feitas análises por EDS do material com granulometria menor que 0,075 mm. As leituras foram realizadas focalizando diferentes partes da amostra para que a análise fornecesse um resultado o mais próximo possível das quantidades reais dos elementos que foram quantificados. A Tabela 1 apresenta a média dos elementos encontrados nas seis leituras realizadas, onde se pode constatar a alta quantidade de oxigênio, cobre, carbono e silício presente nas amostras analisadas. Merece destaque a alta quantidade de cobre, um metal de alto valor agregado.

Tabela 1 - Porcentagem média de elementos presentes na amostra analisada por EDS

\begin{tabular}{cccccccccccccccc}
\hline Elemento & $\mathbf{O}$ & $\mathbf{M g}$ & $\mathbf{S i}$ & $\mathbf{C a}$ & $\mathbf{T i}$ & $\mathbf{F e}$ & $\mathbf{N i}$ & $\mathbf{C u}$ & $\mathbf{B r}$ & $\mathbf{M o}$ & $\mathbf{B a}$ & $\mathbf{A l}$ & $\mathbf{C}$ & $\mathbf{S}$ & $\mathbf{Z r}$ \\
\hline $\begin{array}{c}\text { Média } \\
\mathbf{( \% )}\end{array}$ & 28,49 & 0,12 & 9,57 & 4,75 & 0,56 & 0,84 & 0,61 & 24,18 & 4,38 & 0,72 & 1,17 & 1,26 & 23,22 & 0,01 & 0,10 \\
\hline
\end{tabular}

\subsection{Identificação dos grupos funcionais}

A Figura 2 mostra o espectro de infravermelho obtido para a amostra moída a uma granulometria $0,0375 \mathrm{~mm}$ de placas de circuito impresso de celulares. A partir da análise do espectro foi possível determinar os grupos funcionais e ligações químicas presentes na amostra, apresentados na Tabela 2.

Figura 2 - Espectros de infravermelho da amostra moída de placas de circuito impresso de celulares (Barbosa, 2007).

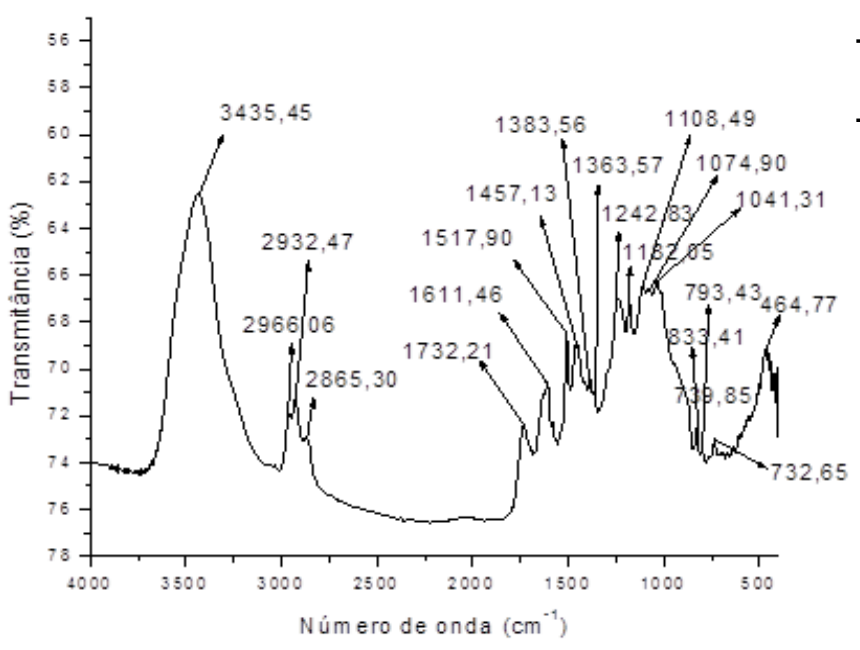

1242,83

1182,05

1041,31

793,43

739,85

Tabela 2 - Grupos funcionais do polímero das placas de circuito impresso de celulares.

\begin{tabular}{cc}
\hline Pico $\left(\mathrm{cm}^{-1}\right)$ & Grupo Funcional \\
\hline 3435,45 & Grupo OH \\
2932,47 & Estiramento C-H \\
1732,21 & $\mathrm{C}=\mathrm{O}$ \\
1611,46 & Estiramento ligações \\
1517,90 & duplas: $\mathrm{C}=\mathrm{C}, \mathrm{C}=\mathrm{N}, \mathrm{N}=\mathrm{O}$ \\
1457,13 & Sais de ácido carboxílico \\
1242,83 & Estiramento C-O \\
1182,05 & C-N de alifáticos \\
1041,31 & S=O \\
793,43 & C-H fora do plano \\
739,85 & Anel aromático \\
\hline
\end{tabular}




\section{Congresso Brasileiro de Engenharia \\ Química em Iniciação Científica \\ Unicamp - Campinas - SP \\ 19 a 22 de julho de 2015}

As bandas de absorção do espectro de infravermelho são referentes aos polímeros e papéis presentes nas placas de circuito impresso. Através da observação dos picos característicos, foi possível identificar que as placas de circuito impressa são compostas basicamente de resinas Epóxi (picos em 833 e $1242 \mathrm{~cm}^{-1}$ ) e Poliéster (picos em 1242, 1108 e $\left.1732 \mathrm{~cm}^{-1}\right)$ (Kasper, 2009). Como essas resinas são matérias termorrígidos, a impossibilidade da fusão dificulta ainda mais a reciclagem destes polímeros (Kasper, 2009).

\subsection{ICP-OES}

Foram realizadas as lixiviações ácidas (água régia, ácida e ácida em meio oxidante) da amostra de placas de celulares em pó e determinação de alumínio, arsênio, bário, cádmio, chumbo, cobre, cromo, manganês, prata, selênio, sódio, ferro, zinco, mercúrio e paládio nos extratos lixiviados. Os resultados obtidos são mostrados na Tabela 3.

Tabela 3: Lixiviação de amostras moídas de placas de CIC obtidos por ICP-OES.

\begin{tabular}{cccc}
\hline & \multicolumn{3}{c}{ Extrato obtido da lixiviação com } \\
\hline Parâmetros & Água régia & Ácido sulfúrico & Meio oxidante \\
Alumínio, $\% \mathrm{~m} / \mathrm{m}$ & $0,382+/-(0,004)$ & $0,79+/-0,01$ & $17,7+/-(0,4)$ \\
Arsênio, $\mathrm{mg} / \mathrm{kg}$ & $114+/-(4)$ & $<10$ & $<10$ \\
Bário, $\% \mathrm{~m} / \mathrm{m}$ & $1,36+/-(0,03)$ & $<9$ & $<9$ \\
Cádmio, mg/kg & $<13$ & $<13$ & $<13$ \\
Chumbo, \% m/m & $1,57+/-(0,02)$ & $43,6+/-(0,4)$ & $42,4+/-(0,4)$ \\
Cobre, $\% \mathrm{~m} / \mathrm{m}$ & $7,4+/-(0,3)$ & $1000+/-(30)$ & $3,11+/-(0,04)$ \\
Cromo, $\mathrm{mg} / \mathrm{kg}$ & $660+/-(20)$ & $46,0+/-(0,2)$ & $<9$ \\
Ferro, $\% \mathrm{~m} / \mathrm{m}$ & $1,21+/-(0,02)$ & $1,05+/-(0,01)$ & $<2$ \\
Manganês, mg/kg & $470+/-(20)$ & $313+/-(1)$ & $32+/-(2)$ \\
Mercúrio, $\mathrm{mg} / \mathrm{kg}$ & $<0,15$ & $<0,15$ & $<0,15$ \\
Paládio, $\mathrm{mg} / \mathrm{kg}$ & $215+/-(9)$ & $<2$ & $<2$ \\
Prata, $\mathrm{mg} / \mathrm{kg}$ & $620+/-(40)$ & $<4$ & $<4$ \\
Selênio, $\mathrm{mg} / \mathrm{kg}$ & $<2$ & $<2$ & $310+/-(2)$ \\
Sódio, $\mathrm{mg} / \mathrm{kg}$ & $320+/-(10)$ & $532+/-(3)$ & $0,161+/-(0,001)$ \\
Zinco, $\% \mathrm{~m} / \mathrm{m}$ & $0,219+/-0,006)$ & $0,106+/-(0,001)$ & $<2$ \\
\hline
\end{tabular}

A partir dessa análise, podemos identificar os metais que se apresentam em maior concentração em cada extrato lixiviado a fim de seguir processos de recuperação de acordo com o metal a ser recuperado. O cobre é o metal que está presente em maior quantidade, de acordo com a análise de EDS, e o de maior valor agregado, e de acordo com a análise de ICP- 


\section{Congresso Brasileiro de Engenharia \\ Química em Iniciação Científica \\ Unicamp - Campinas - SP \\ 19 a 22 de julho de 2015}

OES, encontra-se em maior concentração na solução de ácido sulfúrico e também de ácido sulfúrico em meio oxidante. Portanto, estas seriam as lixiviações mais adequadas para a recuperação deste metal, que após lixiviado, a recuperação deve ser feita através de processos de eletroobtenção (Moraes, 2010).

Identifica-se também alta concentração de chumbo nas lixiviações ácida e ácida em meio oxidante, que é um metal considerado altamente perigoso e, atualmente no Brasil, seus minérios estão praticamente esgotados. A recuperação desse metal através de processo eletrohidrometalúrgico é uma alternativa econômica e ambientalmente adequada.

\section{CONCLUSÕES}

A caracterização de placas de circuito impresso de celulares descartados mostra principalmente a diversidade de elementos contidos no material analisado. Este fato pode ocasionar dificuldades para a recuperação do material presente e sua reinserção na cadeia produtiva. Todavia, esse estudo é relevante para o desenvolvimento de novas tecnologias de reciclagem e reincorporação dos materiais presentes nas placas, que reduziria os danos causados pelo descarte incorreto do material, principalmente pela presença de metais pesados. Pode ser destacada também a alta quantidade de cobre nas placas, identificada a partir das análises de caracterização, metal de alto valor agregado, e possíveis alternativas de recuperação do metal, minimizando impactos ambientais e gerando vantagens econômicas.

\section{REFERÊNCIAS}

YANG, J. et al. Removal force models for component disassembly from waste printed circuit board. Resources, Conservation and Recycling, 53, Tsinghua University, p. 448-454, 2009.

KUNNARI, E. et al. Environmental evaluation of new technology: printed electronics case study, Journal of Cleaner Production 17, Tampere University of Technology, p. 791-799, 2009.

AYRES, R. U. Metals recycling: economic and environmental implications. Resources, Conservation and Recycling, Fontainebleau, France, Volume 21, p. 145173, nov. 1997.

MORAES, V. T. Recuperação de metais a partir do processamento mecânico e hidrometalúrgico de placas de circuito impresso de celulares obsoletos. 2010. Tese (Doutorado em Engenharia Metalúrgica e de Materiais) Escola Politécnica, Universidade de São Paulo, São Paulo, 2010.

BARBOSA, L. C. A., Espectroscopia no infravermelho na caracterização de compostos orgânicos, Viçosa: Ed. UFV, 2007, 189p.

KASPER, A. C. et al. Caracterização de Sucatas Eletrônicas Provenientes de Baterias Recarregáveis de Íons Lítio, Telefones Celulares e Monitores de Tubos de Raios Catódicos. Revista Brasileira de Ciências Ambientais, 12, 2009. 